\title{
Suicidal and homicidal tendencies after Lyme disease: an ignored problem
}

This article was published in the following Dove Press journal:

Neuropsychiatric Disease and Treatment

2 August 2017

Number of times this article has been viewed

\author{
Aitzaz Munir' \\ Muhammad Aadil ${ }^{2}$ \\ Ahmad Rehan Khan ${ }^{3}$ \\ 'Department of Psychiatry, Howard \\ University, Washington, DC, USA \\ ${ }^{2}$ Department of Psychiatry, Rush \\ University Medical Center, Chicago, \\ IL, USA; ${ }^{3}$ Department of Psychiatry, \\ University of North Dakota, Grand \\ Forks, ND, USA
}

\section{Dear editor}

We would like to applaud the author for conducting such an important study by performing a comprehensive assessment of suicide and its association with Lymeassociated diseases (LADs). ${ }^{1}$ It is the first study of its kind, and it raises a need for further investigation on this subject. Suicide is a major health care issue in the USA, contributing to almost 42,773 deaths in the USA in 2014. ${ }^{2}$ There is no data available specific to suicide associated with LAD. Dr Bransfield inferred the possible prevalence of suicide associated with LAD by an indirect method which revealed that 414,540 patients with LAD have suicidal ideation, 31,100 attempt suicide and a total of 1,244 commit suicide in the USA per year from LAD. ${ }^{1,2}$

Several cases have been reported highlighting the issue of an association between suicide and LAD. A case report published in 2013 by Banerjee et al is an example where a case of 44-year-old male without any past psychiatric history presented with a third unsuccessful suicide attempt and was later diagnosed as having Borrelia infection. After 1 month of medical therapy with intravenous ceftriaxone, resulted in improvements in his mental status and resolution of suicidal ideation. ${ }^{3}$ Another set of cases was reported earlier in the 1990s by Fallon et al, highlighting suicidality in patients with Lyme disease. One of the two patients presented with neurological symptoms including fatigue, frontal headaches, and memory loss, and the second with a flu-like illness, joint pain, swollen glands, and fever. After further investigations, both of these patients were diagnosed with Lyme disease and appropriate treatment was offered. Few months after the treatment, both patients developed severe depression along with suicidal threats and an attempt by one patient. An evidence of persistent Lyme borreliosis was found in both cases. ${ }^{4}$ Another study reported in 2002 by Juchnowicz et al suggested that patients with Lyme borreliosis can experience psychiatric issues during both acute and late phases of the disease, most common being depression. ${ }^{5}$ In some cases, it slowly progresses to severity and suicidality as explained in the above cases, but in some cases, it is unpredictable. As evident from the above-reported cases, depression usually precedes suicidality. These reports point to a need of thorough case studies to find a link between such an important association, so that we can treat it accordingly.

Although there is evidence proving the relationship of suicidality with LAD in this study, there is still a need for a more elaborative prospective cohort study highlighting different stages of the disease and percentage of people who develop suicidal thoughts during the disease course and to understand different patterns of development of such thoughts. No direct study has been conducted to estimate the prevalence of patients
Correspondence: Muhammad Aadil 415 Harlem Avenue, Chicago, 60I30, IL, USA

Email muhammad.aadil9@gmail.com 
with LAD who committed suicide or had suicidal ideation. Also, more evidence is needed for a better understanding of the pathophysiology and biochemical mechanisms leading to depression and suicide in these patients. There is also need to explore the relationship of chronicity of Lyme borreliosis with other psychiatric diseases, such as bipolar disorder, leading to suicidal thoughts and attempts.

\section{Disclosure}

The authors report no conflicts of interest in this communication.

\section{References}

1. Bransfield RC. Suicide and Lyme and associated diseases. Neuropsychiatr Dis Treat. 2017;13:1575-1587.

2. Centers for Disease Control and Prevention. Suicide prevention; 2017. Available from: https://www.cdc.gov/violenceprevention/suicide/ index.html. Accessed July 1, 2017.

3. Banerjee R, Liu JJ, Minhas HM. Lyme neuroborreliosis presenting with alexithymia and suicide attempts. J Clin Psychiatry. 2013;74(10):981.

4. Fallon BA, Schwartzberg M, Bransfield R, et al. Late-stage neuropsychiatric Lyme borreliosis. Differential diagnosis and treatment. Psychosomatics. 1995;36(3):295-300.

5. Juchnowicz D, Rudnik I, Czernikiewicz A, Zajkowska J, Pancewicz SA. Zaburzenia psychiczne $\mathrm{w}$ trakcie boreliozy $\mathrm{z}$ lyme i kleszcz zapalenie mózgu [Mental disorders in the course of lyme borreliosis and tick borne encephalitis]. Przegl Epidemiol. 2002;56(Suppl 1):37-50. Polish. 


\section{Author's reply \\ Robert C Bransfield}

Department of Psychiatry, Rutgers-RWJ Medical School, Piscataway, NJ, USA

Correspondence: Robert C Bransfield

225 Highway 35, Suite 107, Red Bank, NJ 0770I, USA

$\mathrm{Tel}+|73274| 3263$

Fax + I 732 74I 5308

Email bransfield@comcast.net

\section{Dear editor}

I would like to thank Munir, Aadil, and Khan for their insightful letter identifying necessary future directions. They recognize the value of accurate and early diagnosis of Lyme and associated diseases (LADs), the value of individualized treatment that includes both antibiotics and traditional psychiatric treatments and future epidemiological and research directions. These efforts could help prevent many tragic suicides. Suicidal and homicidal tendencies after Lyme disease are clearly an ignored problem that deserves greater attention.

The article by Fallon et al that you quoted describes two patients with LAD who were both suicidal and aggressive. ${ }^{1}$ I treated both of these patients, and in addition, I have been able to follow the status of Patient B over a span of 30 years.
This patient was highly suicidal, had horrific intrusive images of killing others, and had violent impulses which were eliminated with treatment. Patient A was also suicidal, violent, and physically assaultive to her son. In both patients, combined antibiotic and psychotropic treatment helped them recover and was clearly life saving. Cases such as these can help explain the pathophysiology of mental illness.

Research in LAD provokes an avalanche of additional questions. Why do only some patients with LAD develop chronic symptoms, mental symptoms, different types of mental symptoms, suicidality, or homicidality? What is the exact pathophysiology, what are the most effective diagnostic and treatment approaches, and how many are actually impacted by these conditions and to what extent? I appreciate the interest expressed by Munir, Aadil, and Khan and look forward to additional interest by others.

\section{Disclosure}

The author has been an expert witness in cases involving suicide and in cases involving Lyme disease. The author reports no other conflicts of interest in this communication.

\section{Reference}

1. Fallon BA, Schwartzberg M, Bransfield R, et al. Late-stage neuropsychiatric lyme borreliosis. Differential diagnosis and treatment. Psychosomatics. 1995;36(3):295-300.

Dove Medical Press encourages responsible, free and frank academic debate. The content of the Neuropsychiatric Disease and Treatment 'letters to the editor' section does not necessarily represent the views of Dove Medical Press, its officers, agents, employees, related entities or the Neuropsychiatric Disease and Treatment editors. While all reasonable steps have been taken to confirm the content of each letter, Dove Medical Press accepts no liability in respect of the content of any letter, nor is it responsible for the content and accuracy of any letter to the editor.

\section{Publish your work in this journal}

Neuropsychiatric Disease and Treatment is an international, peerreviewed journal of clinical therapeutics and pharmacology focusing on concise rapid reporting of clinical or pre-clinical studies on a range of neuropsychiatric and neurological disorders. This journal is indexed on PubMed Central, the 'PsycINFO' database and CAS, and is the official journal of The International Neuropsychiatric Association (INA). The manuscript management system is completely online and includes a very quick and fair peer-review system, which is all easy to use. Visit http://www.dovepress.com/testimonials.php to read real quotes from published authors. 